\title{
Estrutura de capital e estratégias competitivas*
}

\author{
Rogério Sobreira** \\ Felipe Rente*** \\ Claudio Figueiredo**** \\ Classificação JEL: L13; L21; M21. \\ JEL classification: L13; L21; M21.
}

\begin{abstract}
Resumo
Este artigo apresenta um survey dos estudos que destacam os efeitos das decisões de financiamento na capacidade de concorrência das firmas. São descritos os resultados de modelos teóricos e pesquisas empíricas publicados nas últimas duas décadas, enfatizando também as agendas determinadas a partir de trabalhos clássicos sobre 0 tema. Essas pesquisas destacam, principalmente, os aspectos relacionados à responsabilidade limitada dos detentores de capital próprio, os aspectos relacionados à utilização da estrutura de capital para fomentar a concorrência predatória e também os incentivos para o estabelecimento de acordos que limitam a concorrência a partir das escolhas referentes à estrutura de capital da firma. Como as evidências sugerem que há relação entre estrutura de capital e estratégias competitivas, 0 tema torna-se importante para os estudos de finanças e de economia industrial. Além disso, os resultados dessas pesquisas também têm implicações práticas para a formulação de políticas públicas de regulação da concorrência e de incentivo ao financiamento via emissão de dívida.
\end{abstract}

Palavras-chave: estrutura de capital; estratégia competitiva; oligopólio.

\begin{abstract}
This paper presents a survey of studies that emphasize the effects related to financing decisions on the firms' competitive ability. It describes the results of theoretical patterns and an empirical research published during the last two decades and also emphasizes the agenda determined by traditional studies on this subject. Such studies stresses specially the aspects related to the limited liability of the firms' owners, the aspects related to the utilization of the capital structure to stimulate predatory competition and also the incentives to establish agreements keeping limits to the competition, considering the choices related to the capital structure of the firm. Considering that the stylized facts suggest a connection between capital structure and competitive strategies, it becomes an important aspect for finance and industrial organization studies. Besides, the results of theses studies have empirical implications that can give form to public policies regulating competition and stimulating the use of debt as a main financing source.
\end{abstract}

Key words: capital structure; competitive strategy; oligopoly.

\section{Introdução}

Este artigo apresenta um survey que vincula as consequiências das estruturas financeiras ao comportamento competitivo das firmas - e que resultam da conexão entre finanças e economia industrial -, ressaltando que geralmente as firmas conduzem de forma predatória as decisões quanto à estrutura de capital. O levantamento parte das teorias convencionais da determinação da estrutura de capital (MODIGLIANI e MILLER, 1958;

\footnotetext{
* Versão ligeiramente modificada do artigo apresentado nos anais da XXXIX Assembléia Anual do Cladea - Conselho Latino-Americano de Escolas de Administração, realizada na República Dominicana em outubro de 2004.

** Doutor em Economia. Professor de Economia e Finanças, EBAPE/FGV. E-mail: sobreira@ fgv.br. Endereço: Praia de Botafogo, 190, sala 517 - Rio de Janeiro CEP 22253-900.

*** Mestre em Administração pela EBAPE/FGV. Gerente Administrativo do Centro de Pesquisa e Documentação de História Contemporânea do Brasil - Cpdoc/FGV. E-mail: felipe@ fgv.br. Endereço: Praia de Botafogo n.o 190 / 14 andar - Rio de Janeiro - CEP 22253-900.

**** Membro do Instituto Brasileiro de Governança Corporativa (IBGC) e do Instituto Brasileiro de Executivos de Finanças (IBEF). Coordenador de Participações da Petrobras Distribuidora S.A. Professor da FGV Management. E-mail: claudioa@ fgv.br. Endereço: Praia de Botafogo n. 190 / 12 ㅇadar - Rio de Janeiro - CEP 22253-900.
}

Artigo recebido em maio de 2005 e aceito para publicação em julho de 2005. 
ROSS, 1977; MYERS, 1984; MYERS e MAJLUF, 1984; JENSEN e MECKLING, 1976), mostrando como elas podem ser combinadas com teorias convencionais de estratégia competitiva em oligopólio (TIROLE, 1997).

Uma linha de argumentação desenvolvida por Brander e Lewis (1986), Harris e Raviv (1991), Showalter (1995) e Wanzenried (2003) mostra até que ponto a responsabilidade limitada dos detentores de capital próprio afeta as decisões da firma no mercado de bens. Outra linha defende a concorrência predatória, segundo a teoria do "bolso grande" (long purse ou deep pocket), apresentada por McGee (1958) e Telser (1966). De acordo com essa segunda linha de argumentação, uma firma fortalecida financeiramente pode praticar preços abaixo de custo para tirar concorrentes do mercado, o que também é defendido por Bolton et al (2000), Bolton e Scharfstein (1990) e Scott Morton (1997). Existe ainda outro grupo de teóricos que se dedicam a analisar a relação entre o lado financeiro e as práticas de conluio das firmas em oligopólio, num trabalho inicialmente desenvolvido por Maksimovic (1988). Por sua vez, Stenbacka (1994) revê o modelo de Maksimovic, incluindo a variável tributação, para finalmente defender a reafirmação das principais conclusões deste. O mesmo ocorre com Phillips (1995), que mostra que a relação entre estrutura de capital e decisões de concorrência parece estar associada não só à presença de rivais com alto nível de endividamento, mas também à ausência de barreiras à entrada de concorrentes no mercado em escala significativa. Erol (2003) apresenta conclusões semelhantes; enquanto Lord e Farr (2003) testam empiricamente o modelo de Maksimovic em sete empresas da indústria siderúrgica americana no período 1947-80, partindo da hipótese de que a alavancagem e o conluio variam com a elasticidade/preço da demanda.

Um aspecto relevante que este artigo vai procurar refletir se refere às implicações práticas dos resultados dessas pesquisas para a formulação de políticas públicas. Essa nova abordagem sobre a estrutura de capital revela que o endividamento das firmas pode trazer consequiências para a economia que ainda não foram devidamente avaliadas. Se a alavancagem financeira interfere nas estratégias concorrenciais, isso deve ser considerado não só por administradores e investidores, mas também pelo poder público, na implementação de medidas de incentivo ao financiamento das firmas via emissão de dívida e de defesa da concorrência.

\section{Determinantes da estrutura de capital}

O debate sobre a existência de uma estrutura ótima de capital perdura desde que Modigligani e Miller (1958) propuseram que, sob circunstâncias muito específicas, o valor de uma firma não se altera, qualquer que seja o arranjo entre as fontes de financiamento. Em um mundo sem impostos, onde todos os participantes compartilham as mesmas informações, em que pessoas físicas e jurídicas podem tomar recursos emprestados à mesma taxa de juros, não há custos de negociação e os credores são indiferentes ao risco, a estrutura de capital é irrelevante para alterar o valor de mercado e o custo de capital de uma firma, segundo as famosas proposições I e II de Modigliani e Miller. Vários estudos posteriores identificaram alguns elementos que atuam sobre o comportamento das firmas e afetam as decisões de financiamento, colocando à prova a hipótese de irrelevância.

O primeiro desses elementos está associado ao benefício fiscal sobre as despesas com juros. Como tais despesas são deduzidas da base de cálculo dos impostos sobre o lucro das firmas, há um incentivo para a emissão de dívida. No limite, a estrutura de capital ótima seria aquela formada apenas por dívida e nenhum capital próprio. Como a realidade não confirma a presença de uma tal estrutura de capital, a definição da política de financiamento das firmas incorpora outros fatores. Harris e Raviv (1991) e Ravid (1988) citam dois desses elementos como representativos de teorias já bastante avançadas no campo das finanças: os efeitos da assimetria informacional entre os agentes internos e externos e os custos de agência decorrentes dos conflitos de interesses entre esses agentes.

Ross (1977) descreve os efeitos das diferenças de informação disponível para gerentes, detentores de capital próprio, investidores externos e credores sobre a estrutura de capital. $\mathrm{O}$ fato de que os agentes internos dispõem de informações que os agentes externos não têm provoca reações destes, depreciando o valor da firma. Nessa mesma linha de argumentação, Myers e Majluf (1984) afirmam que o fato dos gerentes terem informação 
superior faz da emissão de dívida a melhor opção de financiamento porque os investidores externos assumiriam que a emissão de ações sinalizaria uma notícia ruim. Para Fazzari, Hubbard e Petersen (1988) a assimetria de informação limitaria a capacidade de financiamento das firmas ao filtrar o acesso às fontes de financiamento, na medida em que apenas as grandes corporações estariam em condições de escolher entre recursos internos e recursos externos, para financiar investimentos. O raciocínio é de que há uma hierarquia na decisão de investimento que faz com que as fontes mais valorizadas pela firma sejam esgotadas antes de se partir para o lançamento das ações. Correspondendo a essa hierarquia, as firmas recorreriam em primeiro lugar às fontes internas e, em seguida, aos títulos de dívida para então obter capital através da subscrição de novas ações. Myers (1984) chama essa teoria de pecking order.

A literatura de finanças também considera os conflitos de interesses entre os diversos agentes na determinação da estrutura ótima de capital. Custos de agência decorrem do conflito de interesses entre os detentores de capital próprio e os administradores das empresas, como também entre detentores de capital próprio e credores, considerando que cada um dos agentes procura maximizar seus ganhos. A separação entre propriedade e administração é vista por Jensen e Meckling (1976) como uma nova perspectiva para entender o conceito de firma. Por essa separação, como os administradores não possuem a totalidade da propriedade, a maior parte dos lucros percebidos pelas empresas, em caso de êxito dos esforços gerenciais dos administradores, vai para os detentores de capital próprio. No entanto, os administradores suportam todo o prejuízo quando os resultados das atividades são negativos. Conseqüentemente, tendem a transferir recursos da empresa para fortalecer seu poder pessoal, fazendo os detentores de capital próprio incorrerem em custos para monitorar seu comportamento. A ação dos administradores na defesa de seus interesses, em vez dos interesses da empresa, distancia a estrutura de capital de sua relação ótima por levar a empresa a preferir aumentar seu grau de endividamento. Dessa forma, a alavancagem funciona como um controle das ações gerenciais ao impor limites no uso do caixa da empresa pelo administrador.

A relação entre detentores de capital próprio e credores também está sujeita a conflitos de interesses, os quais estão associados à capacidade dos que têm capital próprio de investirem em projetos cujo retorno positivo será apropriado por eles próprios, mas que, se os resultados forem negativos, os prejuízos serão transferidos para os credores. Isso acontece devido à responsabilidade limitada sobre a dívida contraída pelos detentores do capital próprio. Nessas circunstâncias, estes têm incentivos para investir em projetos mais arriscados, mesmo naqueles que podem apresentar valor presente líquido (VPL) negativo, que leva, naturalmente, à depreciação do valor da dívida.

A teoria dos custos de agência e a teoria da assimetria informacional permitiram avanços significativos na compreensão dos elementos determinantes da estrutura de capital. Contudo, a primeira contribuiu de maneira mais significativa para revelar o comportamento das variáveis estratégicas de concorrência como um fenômeno associado às decisões de financiamento. Particularmente, o conflito entre detentores de capital próprio e os credores é o que apresenta mais implicações por causa da responsabilidade limitada sobre a dívida. Esse aspecto é de importância central no modelo desenvolvido por Brander e Lewis (1986), num estudo considerado por muitos autores como o primeiro a tratar especificamente do assunto. Como será visto mais adiante, a abordagem de Brander e Lewis destaca que a presença de altos níveis de dívida na composição da estrutura de capital tende a tornar os que detêm capital próprio mais propensos a práticas concorrenciais predatórias porque os direitos residuais sobre o valor da firma são dos credores.

\section{Responsabilidade limitada dos detentores do capital próprio}

Brander e Lewis (1986) constatam a insuficiência da teoria das finanças ao tratar isoladamente dos modelos de análise de competição e estrutura de capital. Esses autores argumentam que, apesar de auxiliarem na compreensão de aspectos específicos das decisões estratégicas sobre produção e financiamento, os modelos poderiam contribuir significativamente para a compreensão do comportamento competitivo e das estratégias de financiamento, caso fossem analisados num contexto interativo. Em seu artigo pioneiro, afirmam que uma dívida na composição da estrutura de financiamento de uma firma tende a estimular práticas predatórias dos 
gerentes e detentores de capital próprio. De acordo com tal hipótese, a estrutura de financiamento de uma firma afeta as formas de competição devido ao efeito da responsabilidade limitada dos detentores de capital próprio sobre a dívida. A elevação dos níveis de endividamento amplia o número de estados da natureza em que prejuízos poderão ocorrer, repercutindo também no valor mínimo de retorno necessário para cobrir os custos de produção. Nessas circunstâncias, se as firmas se utilizam da estrutura de capital como elemento estratégico, o resultado final será pior para as mesmas e irá afetar o nível de equilíbrio do produto, elevando-o em comparação com uma situação onde a dívida não seja considerada.

De modo diverso ao conflito de interesses típico dos modelos de custos de agência (JENSEN e MECKLING, 1976), nesse modelo, o conflito entre os que têm capital próprio e os detentores de dívida é evitado quando se assume que o retorno da firma tem caráter endógeno e depende das escolhas referentes ao produto feitas pela firma. ${ }^{1}$ Assim, um aumento no grau de alavancagem estimula os detentores de capital próprio a implementarem estratégias mais arriscadas. Isso decorre da constatação de que a dívida permite a escolha de níveis de produção suficientemente elevados para gerar um alto retorno para a firma, bem acima do valor de face da dívida. Nessas circunstâncias, os detentores de capital próprio absorvem a maior parte dos ganhos. Contudo, caso a escolha da quantidade a ser produzida fracasse diante de uma insuficiência de demanda (assumida como aleatória no momento da tomada de decisão), apenas os detentores da dívida ficarão com as receitas de falência, ao passo que os detentores de capital próprio estarão "protegidos" pelo efeito da responsabilidade limitada. Como resultado, os detentores de capital próprio podem se beneficiar de investimentos mais arriscados (HARRIS e RAVIV, 1991).

No modelo desenvolvido por Showalter (1995), o oligopólio de Cournot é substituído por um oligopólio de Bertrand, de modo que a variável de escolha passa a ser o preço e não mais a quantidade. Nessas circunstâncias, a utilização estratégica de dívida dependerá decisivamente do tipo de incerteza existente no mercado de bens. Se a incerteza prevalecer apenas nas condições de demanda, as firmas tenderão a se utilizar estrategicamente da alavancagem, visto que a mesma leva a um aumento nos preços da indústria e, por conseguinte, dos lucros esperados. Em outras palavras, quando a demanda é incerta, uma firma que aumenta sua dívida otimiza seu retorno (e seu valor) em estados da natureza onde a demanda é mais elevada e, como tal, os preços também são mais elevados. Por seu turno, a firma rival vai reagir elevando seu preço; aumentando, por conseguinte, o lucro esperado da firma alavancada. Nesse caso, tal como em Brander e Lewis, a responsabilidade limitada desempenha um papel fundamental nas escolhas da firma.

Por outro lado, quando a incerteza prevalece em relação aos custos de produção, a utilização de dívida não será uma vantagem estratégica. Nesse caso, a ênfase da firma se volta para estados da natureza onde os custos são inferiores, fazendo com que a mesma privilegie um equilíbrio onde o preço seja mais baixo. Esse compromisso com um menor preço induz a firma rival a baixar seu preço, o que leva a uma redução no lucro esperado da firma alavancada. Assim, as firmas que operam em um oligopólio de Bertrand e ficam em dúvida quanto aos custos não utilizarão a dívida para fins estratégicos.

Outro que também apresenta um modelo baseado no artigo de Brander e Lewis (1986) é Wanzenried (2003). No seu modelo de duopólio de dois estágios com bens diferenciáveis e demanda estocástica, as firmas competem em quantidade ou preço, decidindo antes de tudo suas estruturas de capital para, em seguida, competir no mercado. A novidade de seu modelo está em considerar explicitamente certas características desse mercado, tal como a substitutibilidade entre diferentes variáveis e a volatilidade na demanda, bem como em analisar a imposição de um custo fixo para a utilização do mercado de capitais pela firma. Suas conclusões também apontam para a relação entre estrutura de capital e decisões de produto de uma forma predatória. Em outras palavras, a emissão de dívida no primeiro estágio leva a firma, no segundo estágio, a se comprometer com um comportamento agressivo no mercado. Tal comportamento leva a firma rival a reduzir (aumentar) seu

\footnotetext{
${ }^{1}$ Nesse modelo, a variável de escolha é a quantidade a ser produzida, uma vez que se assume um oligopólio do tipo Cournot como representante da estrutura de mercado na qual a firma está inserida.
} 
produto, no caso de substitutos (complementares) estratégicos ${ }^{2}$ abaixando os preços dos bens ofertados e elevando o lucro esperado da firma alavancada. Como no modelo de Brander e Lewis, a responsabilidade limitada faz com que a firma considere apenas os estados da natureza nos quais a possibilidade de falência esteja afastada. No caso da competição pelo preço (oligopólio de Bertrand), a emissão de dívida induz as firmas a elevarem seus preços, levando a menores quantidades de equilíbrio do produto. Quanto à lucratividade, existe um efeito positivo sobre os lucros realizados, quando os bens forem substitutos, e um efeito negativo, no caso de bens complementares. Quando ambas as firmas seguirem a mesma estratégia de endividamento, o equilíbrio será um equilíbrio de "superprodução" se comparado ao caso de financiamento exclusivamente por capital próprio. Nessas circunstâncias, quando seus produtos forem substitutos, ambas as firmas estarão em pior situação, visto que suas vendas são rivais. No caso de complementos estratégicos, a firma rival vai elevar seu preço, aumentando seu lucro.

Wanzenried também mostra que, quanto mais volátil (incerta) a demanda pelo produto da firma, mais elevado é seu nível de endividamento, pois quanto maior seu nível de endividamento, maior seu lucro esperado: "na ausência de incerteza em relação ao tamanho da demanda, as firmas se financiam exclusivamente com capital próprio; com incerteza em relação à demanda, elas emitem dívida" (WANZENRIED, 2003, p.181). Outro importante aspecto analisado por Wanzenried refere-se ao custo para acessar o capital de terceiros. Suas conclusões indicam que, mesmo com a imposição desse custo, a utilização da dívida ainda será mais lucrativa para a firma emitente, considerando produtos substitutos. No caso de produtos complementares, "a emissão mútua de dívida torna-se vantajosa para ambas as firmas" (ibidem, p.184).

A partir desses modelos, é possível definir os seguintes corolários a respeito da relação entre emissão de dívida e estratégias competitivas:

- corolário 1: a responsabilidade limitada permite a uma firma utilizar estrategicamente a dívida para acirrar a concorrência com firmas rivais, qualquer que seja o tipo de competição (quantidade ou preço);

- corolário 2: diante de incertezas em relação à demanda, a firma que emite dívida estará melhor posicionada estrategicamente que sua rival, qualquer que seja o tipo de competição;

- corolário 3: a utilização de dívida por ambas as firmas faz com que o equilíbrio final do oligopólio seja pior para ambas, qualquer que seja o tipo de competição;

- corolário 4: o tipo de competição só fará diferença na utilização da dívida como elemento da estratégia competitiva se a firma estiver incerta quanto aos custos de produção;

- corolário 5: a substitutibilidade entre os bens das firmas torna a utilização da dívida mais vantajosa para a firma rival, quando os produtos são complementares, e desvantajosa se os produtos forem substitutos, quando a outra firma utiliza a dívida. Quando ambas utilizam a dívida, a vantagem será mútua se os produtos forem complementares.

\section{Estratégias do "bolso grande"}

A teoria "do bolso grande" lançada por McGee (1958) e Telser (1966) é também um exemplo de teoria que relaciona a estrutura financeira com decisões no mercado de bens e, desse modo, complementa a argumentação a respeito do papel da responsabilidade limitada.

De acordo com Telser, a competição em um oligopólio tende a tornar-se predatória quando os participantes disputam retornos monopolistas. Se uma firma tem esse objetivo, terá de enfrentar duas possibilidades: enfraquecer e eliminar os rivais pela redução de seus preços a um nível abaixo dos custos de produção ou

\footnotetext{
${ }^{2}$ Estamos nos referindo à natureza complementar ou substituta dos produtos das firmas. No caso de substitutos estratégicos, os produtos das firmas são rivais. No caso de complementos estratégicos, não existe o efeito da canibalização.
} 
adquirir as firmas concorrentes. Mesmo nesse último caso, a firma que pretende ser monopolista irá travar uma guerra de preços para diminuir os lucros esperados das firmas rivais e reduzir-lhes o valor de aquisição.

A hipótese de Telser é a de que os gerentes comportam-se racionalmente e, por isso, agirão de forma a arcar com o menor custo entre as alternativas viáveis. Portanto, a tônica dessa teoria é a de que a ameaça da guerra de preços é suficiente para que os agentes tomem suas decisões e fujam de uma situação que traga prejuízos para todos. Entretanto, tal ameaça está condicionada à manutenção de níveis de reservas de liquidez, formadas por ativos líquidos e por linhas de financiamento. Tanto a firma que almeja o retorno monopolista quanto as firmas que sofrerão o "ataque" precisam dessas reservas. O pretenso monopolista necessita de recursos para praticar preços abaixo do custo variável médio de longo prazo dos concorrentes e ainda continuar solvente. Os concorrentes precisam das reservas para enfrentar a guerra de preços sem que seu valor de mercado deprecie.

Telser defende que nem sempre a competição predatória é o melhor caminho para atingir lucros monopolistas. A guerra de preços só é vantajosa para a firma que pretende ser monopolista se esta conseguir que seus custos médios mínimos de longo prazo sejam menores do que os custos mínimos médios variáveis de longo prazo dos concorrentes. Quando esses custos diferem muito, o pretenso monopolista tem maiores condições para quebrar seus rivais, pois os concorrentes têm um limite de resistência, determinado pelo tamanho da reserva de ativos líquidos e das linhas de crédito disponíveis. Se os concorrentes tiverem reservas suficientes para suportar preços abaixo do custo variável, conseguirão afastar a possibilidade da guerra de preços e aumentar o preço que o concorrente que pretende ser monopolista terá de pagar para adquirir as firmas concorrentes, porque o pretenso monopolista absorve custos maiores no caso da implementação de uma política de preços baixos de longa duração.

Por esse motivo, o tamanho da reserva de ativos líquidos - tanto para o pretenso monopolista quanto para as firmas rivais - é fundamental no modelo de Telser. Sem ela, não há como ameaçar os concorrentes com uma guerra de preços e não há como os concorrentes aumentarem os preços de aquisição. Portanto, a capacidade de endividamento está intimamente relacionada à decisão concorrencial das firmas. Em um mercado imperfeito, como lembrado pelo autor, a captação de recursos de terceiros é prejudicada pela assimetria de informações, influindo tanto no volume de recursos que as firmas poderão levantar quanto no custo de capital resultante da nova estrutura. Dessa forma, a relação entre estrutura de capital e decisões de produto - que, no caso do modelo de Telser, significa a fixação do preço de produto - ocorre pela incorporação do custo de capital alterado pela necessidade de reservas de liquidez (os ativos líquidos e as linhas de crédito) na aferição do custo dos cursos de ação disponíveis para as firmas. Em outras palavras, o acirramento da concorrência, através de ações predatórias, estaria diretamente relacionado à maior alavancagem.

Vários artigos surgiram após o texto de Telser, apontando a prática racional da predação, não apenas pelo recurso aos preços abaixo de custo, mas também pela adoção de novos conceitos. Ao analisar o cartel do transporte marítimo inglês do século XIX/início do século XX, Scott Morton (1997) aponta o recurso aos preços predatórios contra entrantes em rotas dominadas pelo cartel como uma estratégia adotada abertamente, numa época em que não existiam mecanismos regulatórios. Em sua interessante análise a autora observa que contratos subsidiados pelos governos inglês e alemão para suas frotas - empresas alemãs foram formalmente aceitas no cartel inglês - e a existência de contratos firmes que permitissem a cobertura dos custos fixos tornavam as empresas menos suscetíveis a ataques predatórios. Assim, o conceito do "bolso grande" (a existência de reservas) estava formalmente provado.

A grande contribuição de Scott Morton (1997) foi ter respondido às quatro perguntas que mais interessariam às autoridades regulatórias e financiadoras:

- Como as firmas conduzem sua política de preços predatória?

- Em que ocasiões consideram que essa seja a melhor estratégia?

- Em quais situações?

- Contra quais entrantes a praticam? 
A regressão apresentada pela autora possibilitou testar várias teorias da predação, comprovando que:

- a condução das estratégias dependeria do nível de reservas do atacado, pois entrantes com grandes reservas são mais difíceis de combater, com a tendência de serem aceitos no cartel;

- a estratégia era melhor para firmas com maiores restrições de crédito e menor volume de contratos formais - firmas com receitas incertas;

- nas situações de menor crescimento, o cartel era mais suscetível de realizar ataques para remoção de entrantes, enquanto em situações de estados favoráveis da natureza, com crescimento do comércio, os lucros abdicados em caso de guerra de preços eram maiores. Nessas situações, o cartel preferia acomodar os entrantes e reter os lucros;

- os entrantes com maiores restrições de crédito e menores reservas eram as vítimas da maior parte das ações predatórias, as quais contribuíam para a criação de "uma reputação" dos membros do cartel (BOLTON e SCHARFSTEIN, 1990).

Scott Morton provava, assim, que além da recuperação do investimento na predação, haveria uma segunda forma de recuperação do valor despendido numa guerra de preços: o estabelecimento de uma "reputação" para os agressores, que desencorajaria novos entrantes e pouparia recursos gastos com freqüentes guerras de preço.

Bolton e Scharfstein (1990), por sua vez, mostram que a forma como novas firmas são financiadas pode tornálas vulneráveis à predação. Sua argumentação parte da teoria de agência e da assimetria informacional, considerando que os credores, ao liberarem fundos para as firmas em parcelas (e não integralmente), disciplinam a ação dos gestores da firma alavancada através da racionalização do crédito, evitando o mal uso do capital emprestado. Com isso, desenha-se um contrato que em termos de custo de agência é ótimo, mas cria-se, perante a indústria, condições favoráveis à predação contra aquela firma, reconhecidamente carente de fundos pela disciplina imposta pelo credor.

Dessa forma, a partir da teoria do "bolso grande", temos os seguintes corolários para a relação entre estrutura de capital e estratégias competitivas das firmas:

- corolário 1: quanto menor o acesso ao crédito por parte da firma, maior a probabilidade dela ser vítima de ações predatórias;

- corolário 2: quanto mais incerta a demanda, maior a probabilidade da firma ser vítima de ações predatórias;

- corolário 3: quanto maior a demanda esperada, menor a ocorrência de ações predatórias;

- corolário 4: firmas envolvidas em práticas predatórias são tipicamente financiadas por capital próprio ou possuem rápido acesso a capital de terceiros.

\section{Endividamento e conluio}

Um mecanismo de transmissão adicional das decisões de capital sobre as decisões de competição em um contexto de conluio (colusão tácita) é apresentado em Maksimovic (1988). Ele mostra que as características do setor industrial influenciam na capacidade de alavancagem e manutenção do conluio de um oligopólio ao relacionar os níveis de endividamento com a elasticidade da demanda, com o número de firmas e com a taxa de retorno. O modelo enfatiza a descrição de um mecanismo de manutenção e ruptura de um conluio através da estrutura de capital. Por esse mecanismo, haveria um limite de endividamento suportável pelo conluio, a partir do qual uma firma que superasse esse teto estaria quebrando o acordo.

O oligopólio de Maksimovic é formado por indústrias idênticas que experimentam demandas e custos constantes por períodos infinitos. Também são considerados os custos de agência decorrentes da responsabilidade limitada dos detentores de capital próprio que, junto com a racionalidade dos credores, tendem 
a produzir uma estrutura de capital menos favorável. Assim, as firmas teriam um incentivo para se financiarem apenas com capital próprio. A presença de dívida na composição de sua estrutura de capital estaria sujeita a um limite, pois o nível de endividamento refletiria o acordo entre as firmas. Os desvios em relação ao padrão do oligopólio sofreriam a reação dos competidores com a conseqüente redução do valor da firma desviante. Maksimovic sustenta que o oligopólio obriga os detentores do capital próprio a tomarem decisões de financiamento que não maximizam o valor da firma, repercutindo negativamente sobre a indústria como um todo porque os credores conseguem antecipar as ações das firmas e transferem os custos para os detentores do capital próprio (MAKSIMOVIC, 1988, p.389).

Na concepção de Maksimovic, quanto maior o nível de endividamento das firmas no oligopólio, menor será a capacidade de manutenção do acordo. Por sua vez, o nível de endividamento é inverso ao da taxa de desconto, mas guarda relação com a elasticidade da demanda verificada na indústria, que depende do número e da estrutura de custos de produção das firmas. Um grande número de firmas não é compatível com a manutenção do acordo, já que o volume de produção deverá ser mais elevado do que o nível normal do conluio para que as $n$ firmas tenham seu retorno. À medida que cresce o nível de endividamento, também aumenta o incentivo para a firma produzir mais do que a quantidade de equilíbrio do oligopólio e apropriar-se do fluxo de caixa gerado. Evidentemente, a firma irá preferir os ganhos proporcionados pelo desvio do oligopólio se estes forem maiores do que os ganhos do conluio. Em outras palavras, o valor presente do fluxo de caixa gerado pelo desvio deve superar o valor presente do fluxo de caixa gerado pelo conluio. Implicitamente, Maksimovic retrata as opções da firma como um problema de valor presente, dando à taxa de desconto uma importância capital: se o custo de capital for menor do que o retorno do conluio, a firma não tem motivos para emitir dívida; se, ao contrário, o custo de capital for maior do que o retorno do conluio, a manutenção deste ficará prejudicada.

Stenbacka (1994) reavalia o modelo de conluio apresentado por Maksimovic adotando a variável imposto de renda. Com isso, vai sugerir que a estrutura de capital é resultante das escolhas dos detentores do capital próprio que compensam os benefícios fiscais e as consequiências negativas da dívida. Stenbacka não só reafirma as proposições de Maksimovic - no que se refere à presença de um teto de endividamento que sinaliza a manutenção do conluio - como desenvolve a hipótese de que esse nível de endividamento pode ser uma eficiente barreira de entrada.

Stenbacka apresenta um oligopólio composto por um conjunto de firmas similares que produzem bens (ou serviços) homogêneos e cuja demanda sofre choques aleatórios que têm distribuição normal. As decisões de financiamento são tomadas pelos gestores ou detentores do capital próprio, considerando os benefícios fiscais que o financiamento com recursos próprios não provê, assumindo que a dívida é livre de risco e não leva à falência nas situações de equilíbrio de mercado. Em outras palavras, tais decisões são endógenas, mas baseadas no elemento exógeno dado pela alíquota de tributação. Os lucros ocorrem nos melhores estados da natureza, com choques positivos de demanda. Stenbacka admite que nesse ponto a possibilidade de desvio em relação às práticas do conluio é muito grande, já que os ganhos do abandono superariam os ganhos gerados pela manutenção do conluio. Existe, portanto, um nível de demanda a partir do qual os preços de monopólio praticados pelo conluio são rompidos porque o valor presente das perdas sofridas por uma firma é menor. Stenbacka demonstra que esse nível de demanda diminui com o aumento da alavancagem, o que significa que o endividamento repercutiria negativamente sobre os preços de monopólio, uma vez que o teto para sua sustentação seria reduzido. Em outras palavras, o intervalo de demanda no qual a concorrência é branda em função do conluio entre as firmas tende a diminuir com a elevação da alavancagem. Stenbacka avalia isso com um "aspecto [que] representa um custo de agência da dívida, e que deve ser levado em conta na determinação da estrutura ótima de capital da firma" (1994, p.286) porque a dívida passa a representar um risco com a decisão de abandono do conluio. Conseqüentemente, "a alavancagem financeira elevada diminuirá o valor do capital próprio da firma" (ibidem). Stenbacka conclui que os detentores do capital próprio não teriam interesse contrair dívida se não fossem os benefícios fiscais. Assim, uma estrutura ótima de capital terá em sua composição parcelas de dívida cuja magnitude dependerá das variáveis exógenas (choques de demanda e alíquota de tributação). 
Além dessas considerações, Stenbacka salienta que a redução do teto de conluio com a elevação da alavancagem cria uma barreira à entrada de novas firmas. Os participantes do conluio, ante a ameaça de entrada de uma nova firma, aumentariam seu endividamento acima do nível de rompimento do acordo, reduzindo o preço de tal forma que a firma entrante não teria como competir na nova situação. Nesse caso, "o nível de dívida pode servir como um mecanismo para baixar (numa extensão limitada) a barreira de entrada acima da qual a entrada é detida" (ibidem, p.289).

Lord e Farr (2003), por sua vez, testam empiricamente o modelo de Maksimovic pelo estudo do desempenho de sete firmas siderúrgicas entre 1947 e 1980 nos EUA. Os resultados confirmam a hipótese da presença de um teto de endividamento que sinaliza a manutenção do conluio entre as firmas e apoiam a argumentação de que a alavancagem de conluio varia com a elasticidade/preço da demanda. As premissas desses autores incluem a hipótese de Miller e Modigliani (1961) e Stenbacka (1994) de que as firmas utilizarão o máximo de dívida para se beneficiarem das deduções dos juros sobre a base de tributação. O nível da dívida também sofre a influência dos riscos de falência, no caso de ruptura do desvio, e essa situação incentiva a manutenção do conluio. ${ }^{3}$ Por exemplo, em caso de ruptura do conluio, uma firma que fixa seu nível de endividamento - cujos encargos periódicos estão acima dos lucros do oligopólio - corre o risco de falir, se uma empresa decidir romper o acordo. Outras evidências apontam para um comportamento mais suave da competição, decorrente de decisões de endividamento em indústrias com altos níveis de endividamento, sugerindo práticas de conluio.

Phillips (1995), ao analisar o comportamento dos preços praticados por quatro indústrias - gesso, fibra de vidro para isolamento, polietileno e de trailers -, observou que os preços praticados por três delas (fibra de vidro, polietileno e trailers) subiram após a recapitalização de um grande concorrente entre rivais alavancados, enquanto os preços e margens operacionais caíram na indústria do gesso em resposta ao aumento da alavancagem de uma das firmas. $\mathrm{O}$ autor encontrou uma relação positiva entre altos níveis de dívida e produção na indústria de fibra de vidro para isolamento, na indústria de polietileno e na indústria de trailers. Ao contrário, o endividamento é negativamente relacionado com a indústria do gesso. Ainda que nesse último caso, prevaleça a abordagem de Brander e Lewis (1986), Phillips destaca as diferenças entre a indústria do gesso e as demais: o endividamento não é generalizado, a escala de produção é pequena, a tecnologia é simples e não há fortes barreiras aos que querem entrar no setor. ${ }^{4}$ Isso que significa que a relação entre a estrutura de capital e as decisões de concorrência parece estar associada com a presença de rivais com altos níveis de endividamento e com a ausência de barreiras significativas à entrada e à expansão na indústria (PHILLIPS, 1995, p.192).

Seguindo a metodologia de Phillips (1995), ${ }^{5}$ Erol (2003) analisou a interação entre a estrutura de capital e a formação de preços em oito indústrias manufatureiras e em três indústrias não-manufatureiras turcas, chegando a resultados semelhantes. Entre outras conclusões, Erol (ibidem, p.112) descobriu diferenças nos efeitos provocados pelas dívidas de curto e de longo prazo sobre decisões de produção; sendo que o primeiro tipo implica uma relação positiva e o segundo, uma relação negativa com a fixação de preços de produtos. De modo diferente do que acontece nos demais países em desenvolvimento, os dados revelaram um nível elevado de endividamento de curto prazo, comparável aos países desenvolvidos, e um grau menor de endividamento de longo prazo. Segundo Erol, essas características das indústrias na Turquia evidenciam uma situação de concorrência imperfeita.

$\mathrm{Na}$ indústria norte-americana, na década de 1980, acontecerem uma série de aquisições numa escala sem precedentes, e muitas dessas aquisições foram efetivadas através de alavancagens/aquisições alavancadas (leveraged buyouts - LBO). Chevalier (1995) escolheu aquele momento para estudar a relação entre estrutura

\footnotetext{
${ }^{3}$ Os lucros obtidos pelo conluio são maiores do que os obtidos numa situação de concorrência num oligopólio. A ruptura do conluio por uma firma levaria à concorrência entre as firmas, resultando no equilíbrio de Nash. Portanto, a manutenção do conluio deve ser uma opção racional entre os concorrentes de um oligopólio (MAKSIMOVIC, 1988; LORD e FARR; 2003).

${ }^{4}$ A indústria do gesso analisada por Phillips (1995) tem dois concorrentes principais que dividem $50 \%$ do mercado. A alavancagem não ocorreu nessas firmas, as quais ampliaram sua participação no mercado durante o período analisado.

${ }^{5}$ A metodologia utilizada por Phillips (1995) e Erol (2003) baseia-se em Bresnahan (1989) e Porter (1983). A análise da indústria é feita a partir de dados históricos de preços e quantidades para estimativa das funções de oferta (custo marginal) e de demanda (que deriva da função "demanda" em relação à quantidade). Essa abordagem considera essas funções como não-observáveis e que devem ser inferidas a partir do comportamento da indústria.
} 
de financiamento e decisões sobre produto na indústria de supermercados. A pesquisa parte de dois resultados possíveis, abordados pela literatura, para caracterizar a concorrência quanto à estrutura de capital: ${ }^{6}$ concorrência "suave" (soft) ou concorrência "severa" (tough). Se a concorrência torna-se mais severa, após o anúncio de uma LBO, os retornos obtidos pelas cadeias locais de supermercados deveriam ser menores. Da mesma forma, a competição mais dura deveria afastar alguns rivais das praças onde o concorrente alavancado se instalou. Os dados levantados por Chevalier mostraram que "o valor presente descontado dos lucros futuros de uma cadeia de supermercado sobe quando uma cadeia de supermercados rival anuncia que está assumindo uma LBO ou uma recapitalização alavancada" (CHEVALIER, 1995, p.420). Os dados mostraram, também, que a estrutura dos mercados locais alterou-se com a presença de um rival alavancado, favorecendo a entrada e a expansão das cadeias instaladas com a aquisição de lojas locais. ${ }^{7}$ Baseada nessas descobertas, Chevalier favorece a argumentação de que a competição torna-se mais suave com a incorporação de dívidas na estrutura de capital.

Dasgupta e Titman (1998) procuraram explicar as evidências de concorrência mais branda encontradas nas análises de Phillips e de Chevalier. Segundo seu modelo, a decisão de preço é um problema de desconto de fluxo de caixa e, dessa forma, o custo de capital entra na composição dos preços ao descontar os lucros futuros. Aos clientes, são impostos custos pela troca de produto, o que leva a supor que no futuro será mantida a base de clientes, em decorrência das decisões do primeiro período. Preços baixos tendem a formar uma grande base de clientes no segundo período. Entretanto, altos níveis de endividamento aumentam o custo de capital e diminuem o valor presente dos lucros futuros, desestimulando preços mais altos no primeiro período. Na ausência de dívida, a fixação de preços baixos provoca, num primeiro momento, prejuízos à firma, que seriam contrabalançados no futuro com preços mais altos sobre uma base de clientes maior.

Quando consideramos em conjunto as decisões referentes à estrutura de capital e as estratégias competitivas, enfatizando a prática de conluio tácito, temos, assim, os seguintes corolários:

- corolário 1: existe um teto de endividamento, observável pelas firmas de um oligopólio, que manifesta a adesão das firmas ao conluio. A adoção de níveis de alavancagem além desse limite incentiva o aumento da produção e a concorrência mais agressiva;

- corolário 2: o limite desse teto varia positivamente com a elasticidade/preço da demanda e negativamente com o número de firmas da indústria e com a taxa de desconto. O uso de dívida conversível pode ampliar o limite de endividamento sem provocar desvio do conluio;

- corolário 3: a estrutura de capital pode ser usada estrategicamente para impedir a entrada de novas firmas, elevando-se a alavancagem e reduzindo os preços do oligopólio;

- corolário 4: a superação do teto de endividamento aumento o risco da firma e diminui o valor do capital próprio;

- corolário 5: a estrutura de capital é resultante das compensações entre o benefício fiscal sobre a dívida e os riscos decorrentes do aumento da alavancagem e abandono do conluio.

\section{Conclusão}

Este artigo descreveu algumas das teorias recentes que vinculam a estrutura de capital às decisões de concorrência de produto. Os resultados apurados permitem apontar o comportamento competitivo das firmas como um novo fator determinante da estrutura de capital, por três motivos. Primeiro, a responsabilidade limitada dos detentores do capital próprio sobre a dívida altera os incentivos para a implementação de estratégias de concorrência. Como os credores são os detentores dos direitos residuais sobre o valor da firma, os

\footnotetext{
${ }^{6}$ Chevalier (1995) faz referência aos resultados apurados por Fudenberg e Tirole (1986), Bolton e Scharfstein (1990) e Phillips (apud CHEVALIER, 1995), da corrente que prega o abrandamento da concorrência com o aumento da alavancagem, e a Brander e Lewis (1986), Maksimovic (1988) e Rotemberg e Scharfstein (1990) da corrente que defende o acirramento da concorrência.

${ }^{7}$ Chevalier (1995) observa que o quociente de correlação entre a variação percentual do número de lojas locais e o número de lojas da cadeia que sofreu LBO no período investigado não é significativo. Portanto, a relação entre os dois fenômenos também pode ser explicada por outros fatores.
} 
detentores de capital próprio maximizam o valor de seu investimento apenas nos melhores cenários de realização de demanda e ignoram os cenários de baixo retorno, aumentando a produção e reduzindo preços após a emissão de dívida. Segundo, esses incentivos restringem a capacidade de manutenção de acordos que limitam a concorrência em uma indústria, principalmente se o setor possui um número elevado de firmas e se o produto de concorrência apresentar demanda elástica, condições que tendem a diminuir a taxa de retorno da indústria. Nesses casos, um menor nível de endividamento está associado à intenção das firmas em manter o conluio e auferir retornos mais altos, funcionando, inclusive, como uma barreira efetiva à entrada de novas firmas. Terceiro, a presença de grandes reservas de capital ou a disponibilidade de financiamento estimula práticas predatórias de fixação de preço, ao permitir à firma predadora suportar perdas operacionais.

As teorias discutidas neste estudo apresentam algumas implicações importantes para a teoria de finanças. Os conflitos de interesses entre credores e detentores de capital próprio interferem não só no custo de capital da firma como também nas suas decisões de produção. Portanto, o endividamento contribui para a formação da taxa de desconto do fluxo de caixa e afeta as decisões para a geração das receitas que serão descontadas, potencializando os efeitos sobre o valor da firma. Nesse sentido, cabe observar que a influência dos credores na formação de capital das firmas pelo mecanismo da hierarquia de financiamento alia-se à capacidade de interferência no nível de preços e produção de uma indústria. Além disso, considerando que os credores antecipam as estratégias dos detentores de capital próprio, a manutenção de altos níveis de endividamento deixa de ser vantajosa por causa do aumento do custo do endividamento, fortalecendo a hipótese de manutenção de acordos que limitam a concorrência no oligopólio, através de baixos graus de alavancagem.

A relação entre estrutura de capital e as decisões sobre produto merece atenção não só de administradores e investidores, mas também dos formuladores de políticas de regulação da concorrência e de políticas macroeconômicas. O estudo interativo desses dois domínios - finanças e economia industrial - revela a interdependência das decisões de financiamento e concorrência nos setores oligopolizados e o impacto que causam na produção industrial e nos preços dos produtos. 


\section{Referências bibliográficas}

BOLTON, P. et al. Predatory pricing: strategic theory and legal policy. The Georgetown Law Journal, v.88, p.2239-2330, Aug. 2000.

; SCHARFSTEIN, D. A theory of predation based on agency problems in financial contracting. The American Economic Review, v.80, n. 1, p.93-106, Mar. 1990.

BRANDER, J.; LEWIS. T. R. Oligopoly and financial structure: the limited liability effect. The American Economic Review, v.76, n.5, p.956970, Dec. 1986.

BRESNAHAN, T. F. Empirical Studies of Industries with market power. Handbook of Industrial Organization. R. Schmalensee e R. D. Willig, editores. Elsevier Science Publishers, v. II, p. 1011-1057, 1989.

CHEVALIER, J. A. Capital structure and product-market competition: empirical evidence from the supermarket industry. The American Economic Review, v.85, n.3, p.415-435, Jun. 1995.

CRASWELL, R.; FRATRIK, M. R. Predatory pricing theory applied: the case of supermarkets $x$ warehouse stores. Case Western Reserve Law Review, v.1, p.3-8, 1985.

DASGUPTA, S.; TITMAN, S. Pricing strategy and financial policy. The Review of Financial Studies, v.11, n.4, p.705- 737, 1998.

EROL, T. Capital structure and output pricing in a developing country. Economic Letters, v.78, p.109- 115, 2003.

FAZZARI, S. M.; HUBBARD, R. G.; PETERSEN, B. C. Financing constraints and corporate investment. Brookings Papers on Economic Activity, V.1988, n.1, p.141-195, 1988

FUDENBERG, D.; TRROLE, J. A "Signal-Jamming" Theory of Predation. The RAND Journal of Economics, v. 17, n. 3, p. 366-376, Autumn, 1986.

HARRIS, M.; RAVIV, A. The theory of capital structure. The J ournal of Finance, v.56, n.1, p.297-355, Mar. 1991.

JENSEN, M.; MECKLING, W. Theory of the firm: managerial behavior, agency costs and ownership structure. Journal of Financial Economics, v.4, n.3, p.305-360, 1976.

LORD, A. R.; FARR, W. K. Collusion and financial leverage: an analysis of the integrated mill steel industry. Financial Management, v.32, n.1, p.127-148, Spring 2003.

MAKSIMOVIC, V. Capital structure in repeated oligopolies. RAND Journal of Economics, v.19, n.3, p.389- 407, Autumn 1988.

MCGEE, J. S. Predatory price cutting: the Standard Oil (NJ) case. J ournal of Law and Economics. v.1, n.137, 1958.

MILLER, M.; MODIGLIANI, F. Dividend policy, growth and the valuation of shares. Journal of Business, v.34, n.4, p.411-433, Oct. 1961.

MODIGLIANI, F.; MILLER, H. M. The cost of capital, corporation finance and the theory of investment. The American Economic Review V.68, n.3, p.261-297, June 1958.

MYERS, S. C. The capital structure puzzle. The Journal of Finance, v.39, n.3, p.575-592, July 1984.

- MAJLUF, N. S. Corporate financing and investment decisions when firms have information that investors do not have. Journal of Financial Economics, v.13, n.2, p.187-221, June 1984.

PHILIPS, G. M. Increased debt and industry product markets: an empirical analysis. Journal of Financial Economics, v.37, n.2, p.189-238, 1995.

PORTER, R. H. A Study of Cartel Stability: The Joint Executive Committee, 1880-1886. The Bell Journal of Economics, v. 14, n. 2, p. 301314, Autumn 1983.

RAVID, S. A. On interactions of production and financial decisions. Financial Management, v.8, p.87- 89, 1988.

ROSS, S. A. The determination of capital structure: the incentive- signalling approach. The Bell Journal of Economics, v.8, n.1, p.23-40, Spring 1977.

ROTEM BERG, J. J.; SCHARFSTEIN, D. S. Shareholder-Value Maximization and Product-Market Competition. The Review of Financial Studies, v. 3, n. 3. p. 367-391, 1990

SCOTT MORTON, F. Entry and predation: British shipping cartels 1879-1929. Journal of Economics and Management Strategy, n.679, 1997.

SHOWALTER, D. M. Oligopoly and financial structure: comment. The American Economic Review, v.85, n.3, p.647-653, June 1995.

STENBACKA, J. Financial structure and tacit collusion in repeated oligopoly competition. Journal of Economic Behavior and Organization, v.25, n.2, p.281-292, Oct. 1994.

TELSER, L. G. Cutthroat competition and the long purse. The J ournal of Law and Economics, Chicago, v.9, p.259-277, Oct. 1966.

TIROLE, J. The theory of industrial organization. Cambridge, MA: Cambridge University Press, 1997.

VON HOHENBALKEN, B.; WEST, D. S. Empirical tests for predatory reputation. Canadian Journal of Economics, n.19, 1986.

WANZENRIED, G. Capital structure decisions and output market competition under demand uncertainty. International Journal of Industrial Organization, v.21, n.2, p.171-200, Feb. 2003 